\title{
Asitretin Tedavisiyle Düzelen İki Farklı Tipte Porokeratoz Olgusu
}

\author{
Two Cases of Different Types of Porokeratosis: Improvement with
} Acitretin Treatment

Mine Gökdemir, Aysun Şikar Aktürk, Kürşat Yıldız*, Rebiay Kıran

Kocaeli Üniversitesi Tıp Fakültesi, Deri ve Zührevi Hastalıklar Anabilim Dalı, Kocaeli, Türkiye

*Kocaeli Üniversitesi Tıp Fakültesi, Patoloji Anabilim Dalı, Kocaeli, Türkiye

Özet

Keratinizasyon bozukluklarından biri olan porokeratoz grubunda; dissemine süperfisyal aktinik porokeratoz, punktat porokeratoz, dissemine palmoplantar porokeratoz, lineer porokeratoz ve porokeratozis Mibelli (PM) olmak üzere 5 farklı tip yer almaktadır. Klasik ve en sık görülen tipi PM olup vücudun herhangi bir yerinde görülebilir. Dissemine süperfisyal aktinik porokeratoz ise genellikle güneșe maruz kalan bölgelerde görülen çok sayıda bilateral, simetrik lezyonlarla karakterize diğer bir porokeratoz tipidir. Asemptomatik olmalarına karşın, çeşitli deri malinitelerinin gelişebilmesi nedeniyle tedavi önerilmektedir. Ancak güncel tedavi yaklaşımlarından hiçbiri tamamen etkili değildir. Burada, PM ve dissemine süperfisyal aktinik porokeratoz tanısı konulan ve asitretin tedavisiyle düzelen iki erkek hasta sunmaktayız. (Türkderm 2011; 45: 107-10)

Anahtar Kelimeler: Porokeratozis Mibelli, dissemine süperfisyal aktinik porokeratoz, asitretin

\section{Summary}

There are five different types in the group of porokeratosis which is one of the keratinization disorders: disseminated superficial actinic porokeratosis, punctate porokeratosis, porokeratosis palmaris et plantaris disseminata, linear porokeratosis and porokeratosis of Mibelli (PM). PM is classic and the most common type that can be seen anywhere on the body skin. Disseminated superficial actinic porokeratosis is another type of porokeratosis which is characterized by widespread, bilateral and symmetric eruptions seen on sun-exposed areas. Although they are asemptomatic, treatment is recommended because of the possibility of developing skin malignancies. However, none of the current treatment approaches is fully effective. Here, we report two male patients diagnosed with PM and disseminated superficial actinic porokeratosis who demonstrated improvement with acitretin treatment. (Turkderm 2011; 45: 107-10)

Key Words: Porokeratosis of Mibelli, disseminated superficial actinic porokeratosis, acitretin

\section{Giriş}

Keratinizasyon bozukluklarından biri olan porokeratoz grubunda; dissemine süperfisyal aktinik porokeratoz, punktat porokeratoz, dissemine palmoplantar porokeratoz, lineer porokeratoz ve porokeratozis Mibelli (PM) olmak üzere 5 farklı tip yer almaktadır'. Klasik ve en sık görülen tipi porokeratozis Mibelli olup genellikle sporadik olarak çocukluk yaşlarında ortaya çıkan ve el-ayaklarda daha sık olmak üzere vücudun herhangi bir yerinde görülebilen bir porokeratozdur. Dissemine süperfisyal aktinik porokeratoz ise otozomal dominant geçiş gösteren², genellikle güneş gören bölgelerde çok sayıda lezyonun simetrik olarak yerleştiği bir porokeratoz tipidir'. Bu hastalık grubunda çeşitli tedavi seçenekleri bulunmakla birlikte, güncel tedavi yaklaşımlarından hiçbiri tamamen etkili değildir ${ }^{3}$. Burada, PM ve dissemine süperfisyal aktinik porokeratoz tanısı konulan ve asitretin tedavisinden fayda gören iki erkek hasta sunulmaktadır.

Yazışma Adresi/Address for Correspondence: Dr. Mine Gökdemir, Kocaeli Üniversitesi Tıp Fakültesi, Dermatoloji Anabilim Dalı, Kocaeli, Türkiye

Gsm.: +90 5063663726 E-posta: minegokdemir@gmail.com Geliş Tarihi/Received: 09.07.2010 Kabul Tarihi/Accepted: 17.09.2010

Türkderm-Deri Hastalıkları ve Frengi Arşivi Dergisi, Galenos Yayınevi tarafından basılmıştır.

Turkderm-Archives of the Turkish Dermatology and Venerology, published by Galenos Publishing. 


\section{Olgu 1}

Altmış dört yaşında erkek hasta, yaklaşık 40 yıldır varolan yakınmalarının giderek artması ve iki yıl önce de genital bölgede ortaya çıkan kabarık yaralar nedeniyle polikliniğimize başvurdu. Sistemik muayenesi normal olan hastanın dermatolojik muayenesinde çoğunluğu skrotal bölgede ve penis gövdesinde olan, inguinal bölgede daha az sayıda olmak üzere toplam 10-15 adet, çapları 0,5-1,5 cm arasında değişen, lividi renkli, keskin ve düzensiz sınırlı, çevreleri deriden kabarık papül ve plaklar saptandı (Resim 1a). Alınan deri biyopsisinin his-

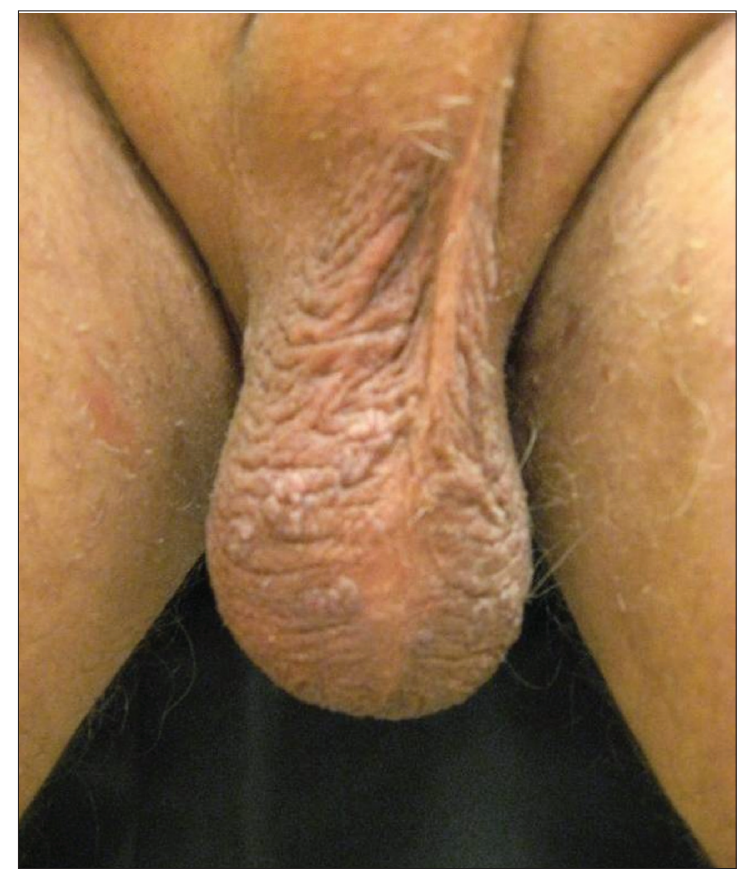

Resim 1a. Skrotal bölgede lividi renkli, keskin ve düzensiz sınırlı, çevreleri deriden kabarık, anüler papül ve plaklar

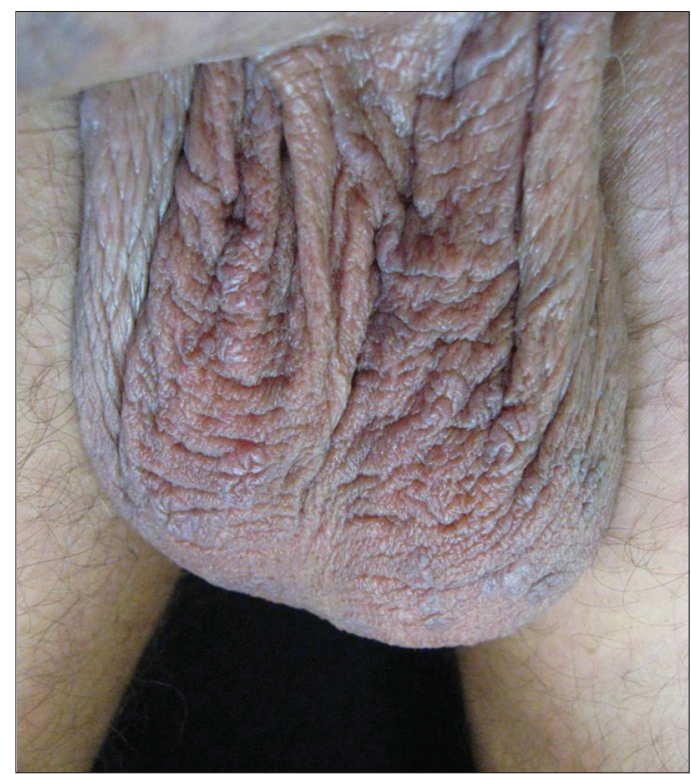

Resim 1b. Tedavinin 1. ayında lezyonlarda belirgin düzelme topatolojik incelemesinde porokeratoz ile uyumlu bulgular tespit edildi (Resim 2). Topikal tretinoin tedavisinden fayda görmeyen, rutin laboratuvar tetkikleri normal olan, klinik ve histopatolojik bulgularla PM tanısı konulan hastaya asitretin 45 mg/gün tedavisi başlandı. Üç ay süreyle bu tedaviye devam eden, şikayetleri düzeldiği için ilacı kendisi keserek takiplerine gelmeyen hasta bir yıl sonra aynı bölgede benzer lezyonların tekrarlaması nedeniyle polikliniğimize tekrar başvurdu. Hastaya 35 mg/gün asitretin tedavisi tekrar başlandı ve tedavisinin birinci ayında lezyonlarda belirgin düzelme gözlendi (Resim 1b). Bu tedaviye bağlı herhangi bir yan etki izlenmeyen hastamızda asitretine dört ay devam edilerek kesildi. Altı ay devam eden takibinde lezyonlarda nüks izlenmedi.

\section{Olgu 2}

Altmış dokuz yaşında erkek hasta, altı yıldır bacaklarda ortaya çıkan, iki yıldır da kollara ve vücuda yayılan lekeler şikayetiyle polikliniğimize başvurdu. Koroner arter hastalığına bağIı stent operasyonu geçiren ve soğuk aglutinin hastalığı olan hastanın sistemik muayenesi normaldi. Koroner arter hastalığı için ramipril, hidroklortiazid ve atorvastatin kullanan hastanın dermatolojik muayenesinde üst ekstremite ekstansör yüzlerde, sternum üzerinde ve bacak distallerinde daha yoğun, sırtta tek tek dağınık halde bulunan, çapları 3-6 mm arasında değişen, ince skuamlı, atrofik görünümlü, yarı keskin sınırlı kahverengi lezyonlar saptandı (Resim 3a). Lezyonlarından alınan deri biyopsisinin histopatolojik inceleme sonucu porokeratoz ile uyumlu bulundu (Resim 4). Rutin laboratuvar incele-

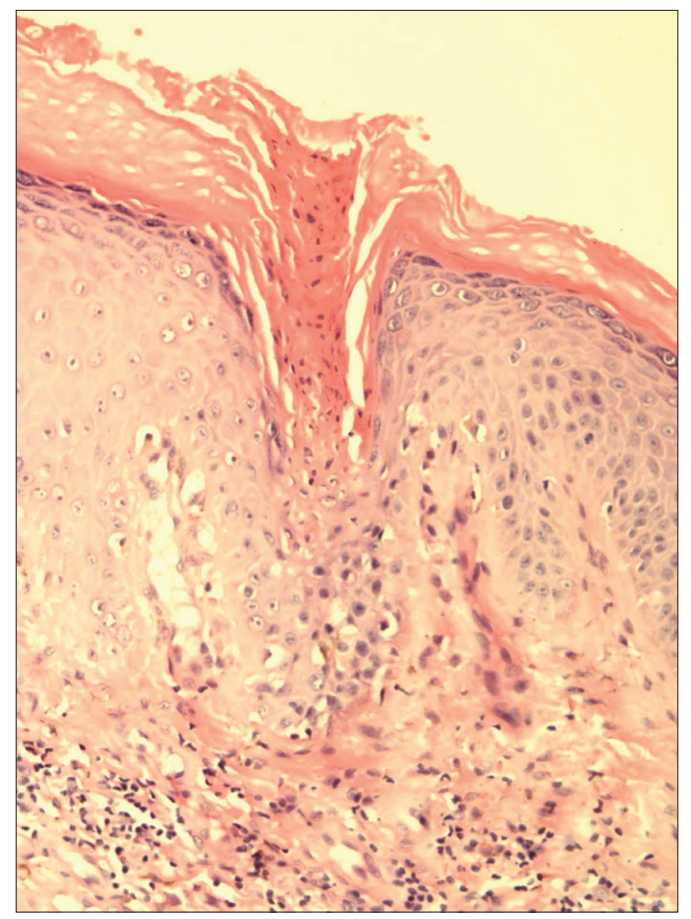

Resim 2. Folikül ağzında genişleme, parakeratotik tabakalanma (kornoid lamella) gösteren keratin tıkaç, epidermiste granüler tabakada belirginlik, hafif derecede düzensiz akantoz, yüzeyel dermiste orta şiddette lenfosit infiltrasyonu (HE x200) 
meleri normal sınırlarda olan hastaya klinik ve histopatolojik bulgular eşliğinde dissemine süperfisyal aktinik porokeratoz tanısı konuldu. Lezyonları yaygın olduğu için 25 mg/gün asitretin tedavisi başlandı ve güneşten korunması önerildi. Tedavinin 2. ayında lezyonlarda düzelme gözlendi (Resim 3b). Hastamızda asitretin tedavisine 5 ay devam edilerek kesildi. Altı aylık takibinde lezyonlarda nüks izlenmedi.

\section{Tartışma}

Porokeratoz nadir görülen heterojen bir hastalık grubudur. Otozomal dominant geçiş göstermekte olup sporodik olarak ve bazı ilaçların kullanılması sonucu oluşan olgular da bildirilmiştir ${ }^{4}$.

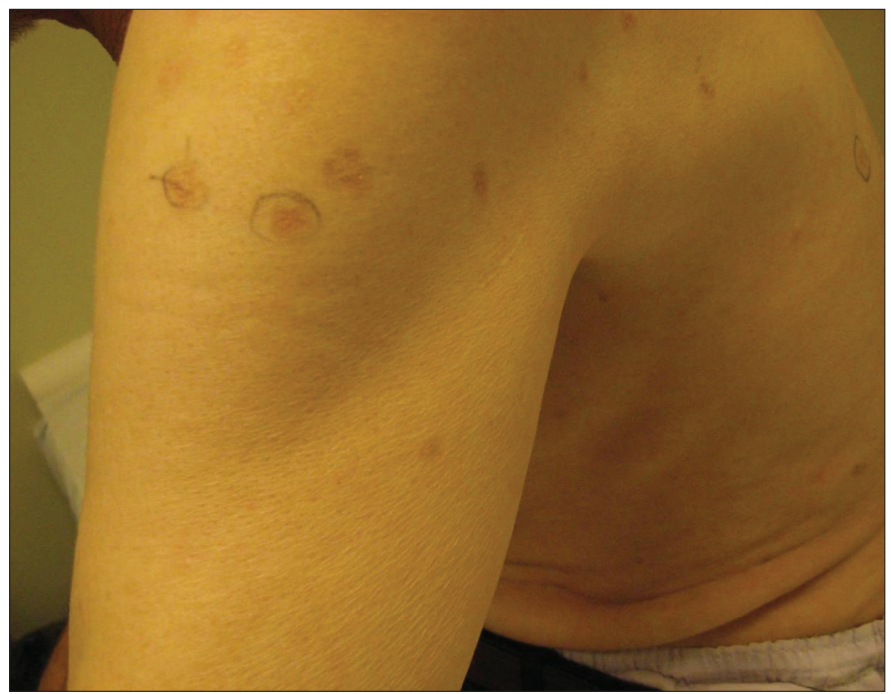

Resim 3a. Sağ omuz üzerinde, ince skuamlı, atrofik görünümlü, yarı keskin sınırlı kahverengi lezyonlar

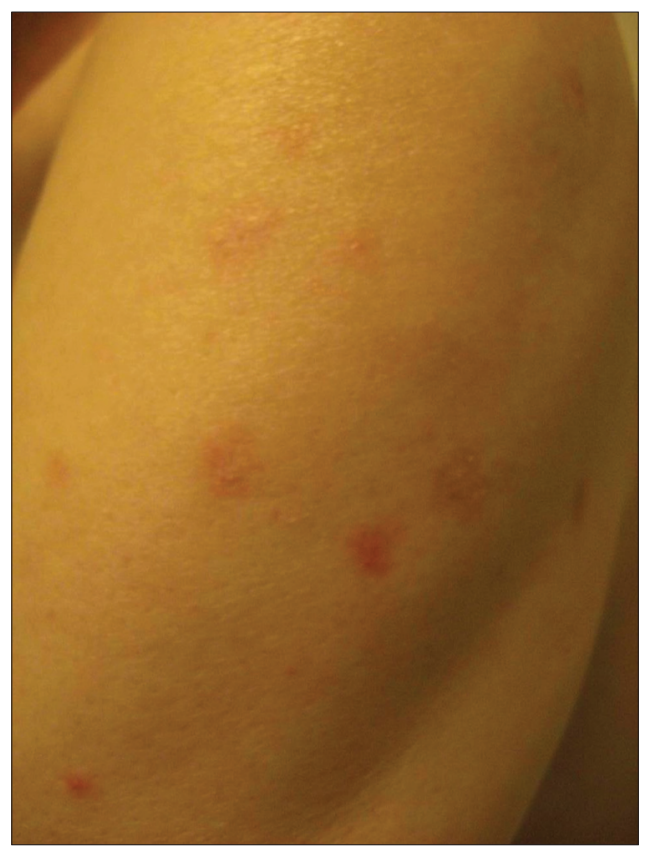

Resim 3b. Tedavinin 2. ayında lezyonlarda belirgin düzelme
Porokeratozis Mibelli genellikle çocukluk yaşlarında ortaya çıkan ve erkeklerde görülen, porokeratozun en sık görülen tipidir. İmmünsüpresif hastalarda erişkin yaşta da ortaya çıkabilen bu tablo küçük, açık kahverengi, keratotik papüller şeklinde başlayan, zamanla genişleyerek kenarları kabarık, düzensiz şekilli anüler plaklara dönüşen lezyonlar ile karakterizedir $^{5}$. El ve ayaklarda daha sık olmak üzere lezyonlar genital bölge ve mukozalar da dahil vücudun herhangi bir yerinde görülebilmektedir ${ }^{6}$. İmmünsüpresyonu olmayan birinci olgumuzda hastalığın başlangıç yaşı, klinik ve histopatolojik inceleme bulguları porokeratozis Mibelli ile uyumlu idi.

Güneş gören bölgelerde, simetrik yerleşim gösteren ve immünsüpresyonla yakından ilişkili olan dissemine süperfisyal aktinik porokeratoz ise genellikle 20-40 yaşlarında ortaya çıkmakta ve kadınlarda daha sık görülmektedir. Genellikle yoğun ultraviyole maruziyeti öyküsü olan bu hastalarda ilaçlara bağlı fotosensitivite de etyolojide rol oynayabilmektedir. Lezyonlar kol ve bacakların ekstensör yüzlerinde çok sayıda, küçük çaplı, yüzeyel ve belirgin olmayan anüler, keratotik kahverengimsi lezyonlar şeklindedir'.

Dissemine süperfisyal aktinik porokeratozu olan ikinci olgumuzda lezyonlar daha çok güneş gören bölgelerde yer almaktaydı. Ayrıca, güneş maruziyeti öyküsü olmayan hastamız 20 aydır porokeratoza neden olmayan, ancak fotosensitif etkisi olan ramipril, hidroklortiazid ve atorvastatin kullanmaktaydı. Soğuk aglutinin hastalığı bulunan ve bu açıdan hematoloji bölümü tarafından takip edilen hastada herhangi bir immünsüpresyon yaratan durum saptanmadı ve soğuk aglutinin hastalığının idiyopatik olabileceği söylendi.

Porokeratoz lezyonları üzerinde deri malinitelerinin oluşma riski yüksektir³. Özellikle büyük çaplı olan, uzun süreli bulunan ve lineer tip porokeratozda bu risk daha fazladır ${ }^{7}$. Literatürde farklı tipteki porokeratoz vakalarında \%10 oranında Bowen hastalığı4 ${ }^{4}$, skuamöz hücreli karsinom ${ }^{4,8}$ ve daha nadiren

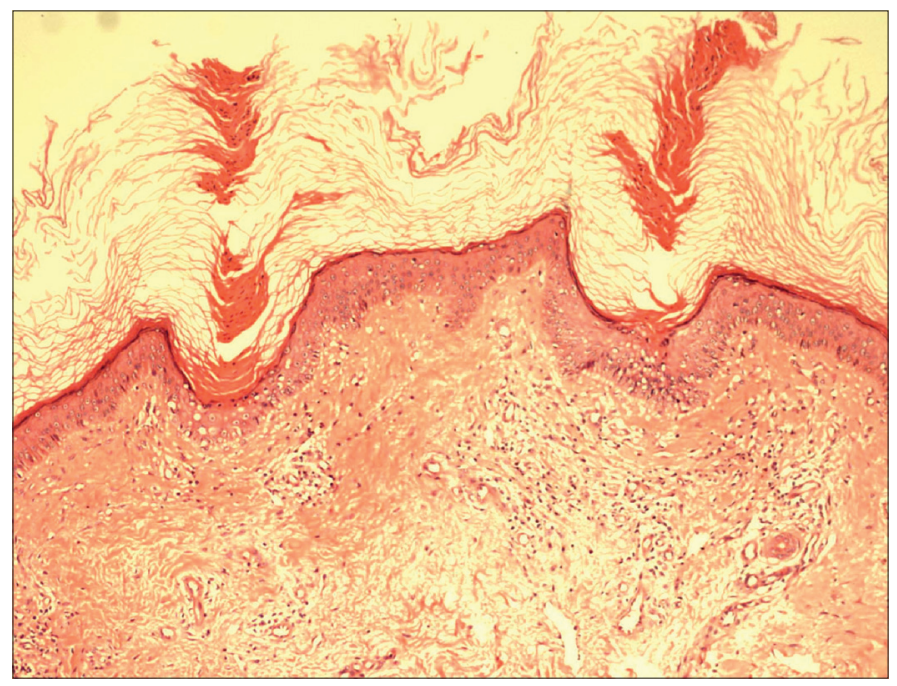

Resim 4. Folikül ağızlarında belirgin genișleme, parakeratotik tabakalanma (kornoid lamella) gösteren keratin tıkaçlar, yüzeyel dermiste damarlar çevresinde yoğunlaşan lenfoid infiltrasyon (HE x100) 
bazal hücreli karsinom ${ }^{4}$ geliştiği bildirilmiştir. Bizim iki olgumuzda da porokeratoz dışında deri tümörü dahil başka bir deri hastalığı tespit edilmedi.

Porokeratozis Mibelli tedaviye dirençli bir tip iken, dissemine süperfisyel aktinik porokeratozda ise ultraviyoleden korunma ile spontan düzelme sağlanabilir. Buna rağmen malinite gelişme riski nedeniyle tedavi edilmeleri önerilmektedir ${ }^{3}$.

Porokeratozların tedavisinde topikal 5-florourasil, kalsipotriol, imikimod, kriyoterapi, dermabrazyon, elektrodesikasyon, CO2 lazer, 585-nm pulsed dye lazer, Nd:YAG lazer, sistemik olarak oral isotretinoin ve asitretin kullanılmaktadır ${ }^{9}$. Asitretin etretinatın aktif metaboliti olan ikinci jenerasyon monoaromatik retinoidtir. Porokeratozdaki etki mekanizması tam olarak bilinmemekle beraber çeşitli keratinizasyon hastalıklarında epidermal hücrelerin yenilenme hızını azaltarak etkili olduğu düşünülmektedir ${ }^{9}$. Ayrıca oral retinoidlerin kullanımının, özellikle immünsüprese hastalarda daha fazla olan deri malinitelerinin oluşma riskini azalttığı bildirilmiştir'. Literatürde özellikle etretinat ile başarı sağlanmış porokeratoz vakalarına rastlanmıştır ${ }^{9,10,11}$.

Hong ve ark.'ları yaygın lineer porokeratoz tanısı konulan 50 yaşında bir bayan hastaya $30 \mathrm{mg} / \mathrm{gün}$ asitretin tedavisi başlamış. Daha önce uygulanan laser dermabrazyon, topikal tretinoin, imiquimod ve tazoroten tedavilerden fayda görmeyen bu hastada bir ay içinde klinik düzelme, 7. ayda ise hem klinik hem de histopatolojik düzelme tespit etmişlerdir ${ }^{9}$.

Bizim hastalarımızda da asitretin tedavisiyle lezyonlarda belirgin gerileme izlendi. Birinci hastamızda asitretin tedavisine 4 ay devam edilirken, ikinci hastamızda 5 . ayda klinik düzelme gözlendiği için tedavi kesildi.
Farklı tipte ve lokalizasyonda porokeratozu bulunan bu iki olgu; porokeratozun nispeten nadir görülen bir durum olması ve asitretin tedavisi ile belirgin düzelme sağlanması nedeniyle sunulmaya değer bulundu.

\section{Kaynaklar}

1. Spencer LV: Porokeratosis. eMedicine website. Available at http://www.emedicine.com/derm/topic343.htm.

2. Wu LQ, Yang YF, Zheng D, et al: Porokeratosis. eMedicine website. $\mathrm{Br}$ J Dermatol 2004;150:999-1004.

3. Montes-De-Oca-Sanchez G, Tirado-Sanchez A, Garcia-Ramirez V: Porokeratosis of Mibelli of the axillae: treatment with topical imiquimod. J Dermatolog Treat 2006;17:319-20.

4. Rongioletti $F$, Rebora A: Disseminated porokeratosis with fatal metastatic squamous cell carcinoma:an additional case of 'malignant disseminated porokeratosis'. Am J Dermatopathol 2002;24:144-8.

5. Bencini PL, Tarantino A, Grimalt R, Ponticelli C, Caputo R: Porokeratosis and immunosuppression. $\mathrm{Br} J$ Dermatol 1995; 132:74-8.

6. Dolar N, Serdaroğlu S, Demirkesen C: Porokeratozis Mibelli histolojisi gösteren dissemine süperfisyal aktinik porokeratoz olgusu. Türkderm 2003;38:220-3.

7. Sasson M, Krain AD: Porokeratosis and cutaneous malignancy. A review. Dermatol Surg 1996;22:339-42.

8. Cort DF, Abdel-Aziz AH: Epithelioma arising in porokeratosis of Mibelli. Br J Plast Surg 1972;25:318-28.

9. Hong JB, Hsiaso $\mathrm{CH}$, Chu CY: Systematized linear porokeratosis:a rare variant of diffuse porokeratosis with good response to systemic acitretin. J Am Acad Dermatol 2009;60:713-5.

10. Danno K, Yamamoto M, Yokoo T, Ohta M, Ohno S: Etretinate treatment in disseminated porokeratosis. J Dermatol 1988;15:440-4.

11. Goldman GD, Milstone LM: Generalized linear porokeratosis treated with etretinate. Arch Dermatol 1995;131:496-7. 